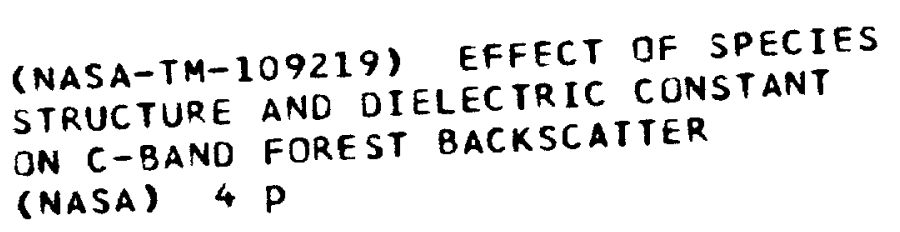

N94-11885

Unclas

$G 3 / 43 \quad 0176670$ 


\title{
EFFECT OF SPECIES STRUCTURE AND DIELECTRIC CONSTANT ON C-BAND FOREST BACKSCATTER
} P.

\author{
R. H. Lang'. R. Landry', Ö. Kulıç \\ N. Chauhan', N. Khadr', D. Leckie
}

\author{
'The George Washington University, Washington. D.C. 20052 \\ :Canada Centre for Remote Sensing. Ottawa, Ontario, Canada K1A OY7 \\ 'NASA Goddard Space Flighi Center, Greenbelt, MD 20771 \\ 'Forestry Canada. Petawawa National Forestry Institute, Chalk River. Ontario. Canada KO1 LO
}

\section{ABS TRACT}

A joine experiment between Canadian and USA research teams was conducted early in October. 1992 to determine the effect of species structure and dielectric variacions on forest backscacter. Two stands, one red pine and one jack plne, in the Petawawa vacional Forescry Instelece (PNFI) were Petawad for the experiment. Extensive tree wtilized for the experiment. excenstve by the architecture measurements had been taken by the months eaclier by employlng a Total station surveying instrument which provides detalled information on branch structure. A second part of the experiment consisted of culter do measure trees and using dielectric probes to measure sizes

The dielectric and the tree geometry data have been used in the George Washingeon University (CrJ) Vegeration Model to determine the $C$ band backscattering coeffictents of the individual stands for $W V$ polartzation. The model results show that backscarter at $C$ band comes mainly from the needles and small branches and the upper portion of the =runks acts only as an actenuator. The paper will conclude with a discussion of varlacion of backscatter with specle structure and how dielectric vartaclons in needles for both spectes may affect the total backscatter returns.

Keywords: Forest, backseatering, wicrowave.

\section{INTRODOCTION}

A joine experiment between Canadian and USA research teams was conducted late in September. sese effect of species structure and dielectric constant on forest radar backscatcer. Two stands, one red pine and one jack pine, in the Petawawa Naclonal Forestry Institute (PNFI) wer urilized for the experiment. $C$ and $X$ band daca was obealned from over-flights by the bCRS cree archleecture and branch and needle dielectric cree archicects date was then used in the GWU constants. This data was model and measurement results could be compared.

the two test sites wer located inside the PNFI research forest which is centered at $46^{\circ} 00 \cdot \mathrm{N}$, $77^{\circ} 25^{\circ}$, near Chalk Rivar, Onterlo, Canada. Both cest sites were characteristic of plantacion stands having even age trees which were planted on flat ground in a regular fashion. The red pine flat ground thes as extent of 4.0 stand ( $P$ inus resinosa), which has an excent with an hectares, consisted of 58 year old trees with an average dlaneter at broast helght (dbh) of 23 . and a helght of $21 \mathrm{~m}$. The fack pine stand (Pinus banksians) consisted of 26 years old trees which they covered a 3.5 hectare area. The previous July (1992), as part of an optical experiment. careful architectural measurements using a vectorization rechnique were made of three trees in each stand technique were matime of the over-flights delectric measurements of branches and needles were made at $C$ and $X$ bands by using Applfed Microwave portable dielectrlc meter with tree probes. The CCRS dielectic meter wien over the sltes on seprember 25 afrborne SAR flew over the sltes on septemer 25 and 26.1992 . The flights were coordinated with thus corner reflectors and active radar callbracors (ARCs) were in place for calibration purposes. On September 25 th like and cross polarized data was obcained az $C(5.3 \mathrm{GHz})$ and $X$ ( $9.25 \mathrm{GHz}$ ) band for several angles of inctdence. on the following day, polarimetrle daca was collected at $C$ band. The weather at the time of corh over-flighes was clear and dry. In the presene papar only $C$ band $W V$ polartzed daca will be employed.

Several researchers have been interested in tree structure and dielectric constant as a mechanisa for using radar to classify trees by mechanisa for using radar there is some evidence specie. In the literacure there is some evidence $C$ and $x$ band SAR data has demonstraced that andeablo dfferences extst between backscatter values for different tree types in the PNFI values for different ${ }^{2}$, employing JPL SAR P, L and $C$ band measurements made $f \Omega$ North Michigan, and $C$ band measurements made li Norther stands has shown that both declduous and conlfer scands have discernible backscatter differences over the spring to sumer elme-frame. Lang. et al: 3 ! has shown how the long stralght erunks of the red pine are partially responsible for the bright returns observed at $p$ band. Salas, et al $[4]$ and McDonald. et al (5) have demonstraced how the dielectric constant in the active xylem responses to water condftions in the tree. These changes in dielectric constant in the outer sapwood may effect backscater values particularly at $C$ and bands where the penetracton of electromagnetfc waves is saall.

\section{TREX ARCAITECTURI MEASURDOENTS}

Treo archicecturo daca was collected using a cechnique called "Tree Vectorization" now cechnlque Canede Centre for Renote Sensing. developed at the Canade Cencre for Remoce Sensing. The wothod was doveloped to characterte and to architecture frov a restricted daca sample and co use this sample to reconstruct a statscleally accurete 3-dimenalonal representation of the tree. Landry, of a $[6]$. The aethodology can be used for tree and forest canopy modeling research in spectrum. 
The vectorization method involves daca collection at irree different levels: the trunk inventory, the branching structure, and the foliage daca collection. Each has a specific nethodology and provides a separaze set of data. The spatial distribution of the supporting or the frimary bzasthes, is chazackazized liviuugh the crunk inventory. The branch structure is specified by a vectorized sampling method, and concurrenty, follage daca is recorded for individual branch components. Finally, the information, which is collected at all levels, is combined at the final stage and used for tree reconstruction.

Briefly, the sampling strategy proceeds by first making a trunk inventory. The spatial distribution of all major branches that leave the trunk along with theli diameter and elevacion angle are recorded. The branch structure is defined by sampling a suffleient number of primary branches co get a represencacive variation of the branch structure along the tree teight axis.

The structure of these selected branches is characterized in terms of branch segments. Each segment corzesponds to that portion of the branch between two branch nodes or ramiflcation polncs. A seiteited number of connected oranch segwencs or paths are designated for sampling and the spatial locacion of each segment's nodes is recorded using a surrey instrument (Wild TC1000 Total stacion). The precision of this instrument is more than adequate for these purposes since it is within 3 min in a $2 \mathrm{~km}$ range, and within 3 seconds of arc in horizoncal and vercical angles. Each sampled segment is tagged and actrtbutes such as segment number, connecting segmene numbers, dlameter and follage information are recorded.

From the sampled branch informacion and the trunk invencory, the 3 dimenslonal architecture of the complete tree can be reconstructed. The reconstruction is not exact since sililarity principles are employed to reconstruce whole branches from the sampled portfons. The reconstructed branches are then used to represent other primary branches on the trunik that were not selected for sampling. In this way an approximate representation of the tree in terms of segments whose coordinates are known is obtained. The method is discussed in more detail in Landry [6].

The vectorized sampling and reconstruction rechnique has been used so model one typlcal tree in the red pine stand and one in the jack pine stand. From the reconstructed trees. segment data has been used to determine branch pachs. Since the segmencs in each branch are not necessarily collinear, the reconstructed branches are, in general, curved. Since branches used in the scattering model are cylinders, the reconscructed branches were replaced by cylinders that have the mean dlameter and the wean levation angle of the reconseructed branch. These averages are deflned by welghting each segment's diameter or elevation angle by 1 ts lengeh. These mean branches or cylinders are then classifled into size categories based on their diameter and branch length distributions: these distributlons are determined from all the reconstructed branches in the tree. The branch classes are listed in Table 2. A twig class has been created since twigs don't usually occur at nodes and thus must be treaced specially. Also the branch class 0 tends to reflect the cerminal gegments found in the tree. The cerminal segment class and twig class have simllar statistes in teros of mean diameter and length.

The probability density functions of branch lengeh, mean branch diarteter and nean branch elevacion angle and the densiz: of branches per cubic meter were derived for each branch class The number of reedles was calculazed by using the inforration collected per segment trotal length of segment ith needles, percentage of needles and

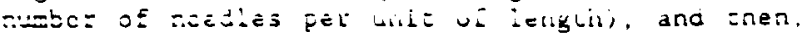
by summing segment values oycr tie thole tree

\section{DIELECTRIC CONSTANT MEASUREMENTS}

Detailed measurements of the dielectric constant for a red pine and a jack pine tree were made using a dielectric probe. The use of a dlelectric probe to obcain dielectric constant values was preferred over the empirical approaci used by the authors in the past since the probe measures the dielectric constant directly. The empirical approach estimates the dielectric constant and this escicace is primarily dependent upon molsture conterss of the vegetation. Importart electromagnetic parameters, such as ionic conductivity is usualiy assumed to be the same for all pares of a tree. The aim of the probe measurements, in the present experiment, was to investigate: 1) differences in the dielectzic constants of different species, 2) differences in the dielectric constant in the same species. At the time of the experiment, it was thought that at $C$ band, the trunk of a tree is less important than the crown. Therefore, the dielectrlc constant measurements were limited to the branches and the needles only. The measurements on branches were done in the flelds, whereas, the clusters of needles were sealed in plastlc bags and their

dielectic

The live crown of a red pine and a jack pine cree was divided Into three segments. A typical branch from each segment was selected. The branch was cut into three parts. To study the differences in dielectric constant as a function of depth inside a branch, the cross-section of a branch was divided 1nco three annular regions. The region fust beneath the bark was called outer region. The center part. looking Into the cross-section of branch was called fnner reglon. The remaining area between the outer and inner reglons was called middle reglon. Probe measurements across the cross-section of a branch segment were taken in each of the regions. It was found that values for the cencer and oiddle roglons were of the same order. As a result, the center region was expanded to encompass the widdle region to simplify the discussion. Fig. 1 shows a typical branch cross section with the two regions labeled. The outer region has a wideh $L$ while the radius of the center region is $\mathrm{L}_{\text {e }}$

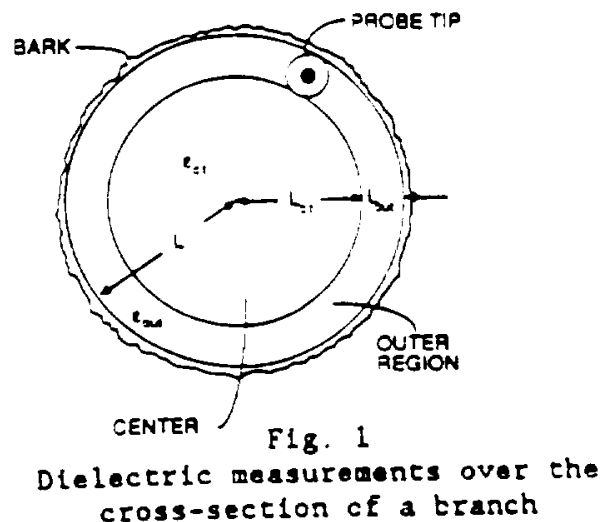


is an illustzation, the real part of the geasured dielectic values from a red pine tree for the cencer and outer regions are ploteed in Fig. 2. The imaginary part is found to follow the ame crend, and cherefore is not shown in the igure. The differences in the dielectric constant

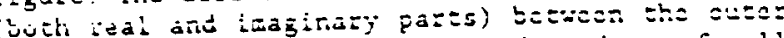
and center regions exist for branches of all diameters. The high values of dielectric constant that are obserred in the outer region are most likely due to sap and water cransport layers that likely due to sap and thation has a chickness, $L$, of $3 \mathrm{~mm}$. This thickness is decermined by the probe ip width. It should be noted from Fig. 2 that the outer and center dielectric appear to converge as the diameter of the branch becomes smaller. This is because the minimum resolution of the probe tip makes it increasingly difficult to resolve outer and cencer regions for small branch diameters. It should be mentioned here that the data from all segments of the tree are merged together to obcain Fig. 2

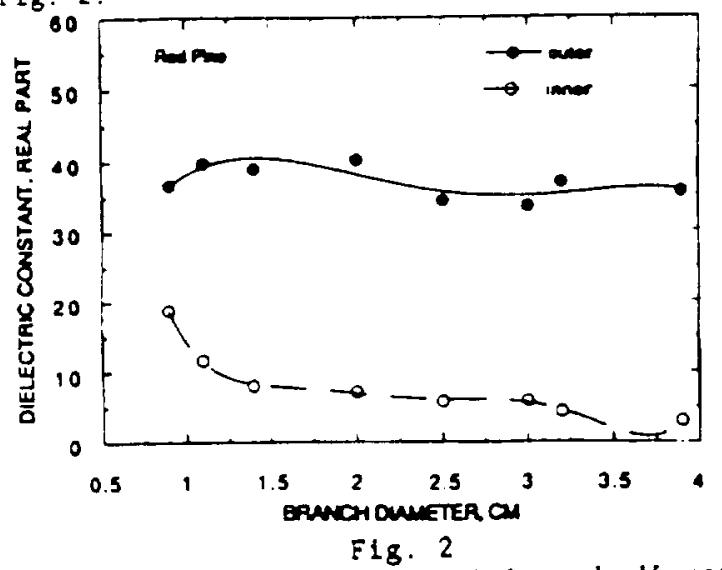

Dielectrle varlations with branch diameter

In order to measure the dielectric constant of needles, a hose clamp was used to bundle the reedles tightly cogether. The clamp was squeezed so as to remove the ait gaps among the needles. Care was taken not to crush the needles by over-squeezing the clamp. The bundle was cut in half to obtain a flat face of the needles. A mean of five probe readings taken across the cross-section of the bundle was used to specify the dielectric constant of the needles. Four bundles of needles were used for dielectric constant measurements.

TABLE 1

Compartson of Mean Values of Real and Imaginary Part of Dlelectele Constane

\begin{tabular}{|c|c|c|c|}
\hline Scatterer & Type & Red PIne & Jack PIne \\
\hline Branch & $\begin{array}{l}\text { Center } \\
\text { Outermose }\end{array}$ & $\begin{array}{l}(16.7,3.9) \\
(37.1,16.7)\end{array}$ & $\begin{array}{l}(3.8,2.0) \\
(25.3,10.5)\end{array}$ \\
\hline Needles & & $(13.4,5.4)$ & $(13.3,5.6)$ \\
\hline
\end{tabular}

It took 4 days to complete dielectric constane measurements. The measurewents for branches of a red pine tree were made mostly during the mornings and the jack pine data were collected in the afternoon. The callbration accuracy of the probe was checked perlodically by using standerd liquids such as butanol, echanol, metharol formamido, ctc. Table 1 sumartzes verage resulis from branches ard needles for red pine and jack pine trees. The species difference are cleatly nociced in the case of branches. hile for needles such differences are not found. We also determined wet and dry weights of the branch segments and the needles. The moiscure cancenze vere determined fzom tois taza faz horh species. No significant differences in moiscure contents were discovered between the red pine and jack pine -..es

\section{FOREST MODEL}

The forest is modeled as a two layered random medium with a rough surface beneath. The tree components such as branches, needles, and trunks are distributed in the medium according to their measured orlentation statistics. The distorted Born Approximation is used to compute the total backscatrering coefficient, $a^{\circ}$, for the forest.

The rotal return can be expressed as a sum of the direct. direct-reflected and surface backscatter terms; however at $C$ band the rain contribution is observed to be from the direct term only. The geometric parameters of the forest medium; such as densley, scatcerer sizes and oriencacions are obtained from the eree vectorization data. For wudeling purpustes, the small size branches and che twigs of the vectorlzation method were classified as secondary, and the branches which were larger were named as primary. The probability density function for the needles for both red pine and jack pine stands were chosen as sin $2 \theta$. for $0 \leq \theta \leq 90$ degrees. The secondary and primary branches for these stands were assigned unlform distributions whose end points were estimated from the vectortzed data.

The dielectric measurements were made for the outer and center parts of the branches, as seen in F1g. 1. The data for these reglons was used to determine the dfelectric constant of an equivalent, homogeneous branch of the same size. As seen in Fig. 1. the outer part of the branch, which has the highest dielectric value is assumed to be as thick as the probe tip. The thlckness of the center and outer parts are denoced by $L_{c f}$, and $L$ respectively. $\epsilon$ and $\epsilon$ ous represent the dielectric constants for these regions and are determined from the measuremencs. An average dielectric value, $\epsilon$ for an equivalent branch of the same slze is then calculated by using

$$
k_{0} n_{a=} L-k_{0} n_{\text {our }} L_{\text {our }}+k_{0} n_{e s} L_{\text {se }}
$$

where $n$ is the refractive index and is given by the square root of the dielectilc constant. The right hand side of $\mathrm{Eq}$. (1) represents the complex phase fron the branch surface to lis center. This is equated to the complex phase for a homogeneous branch of peraiteiviey 'a. It should be noted that this approach will be valld only for the cases when the skin depth exceeds $L$. As the skin depth gets saller. the dielectric conscant should approseh the dielectric value of the outer part. However. Eq. (1) w111 not differentiate between these cases and will underestimate the average permitclivity when the skin depth is less than $L$. peralct bo sumarizes the values for the model paramecers for red pine and jack pine stands as dertued froa the vectorized geometric data and $E q$. (1) The trunk layer has been excluded since at (1) band backscattering coefficient originates matnly fron the tree crown 
TASLI 2

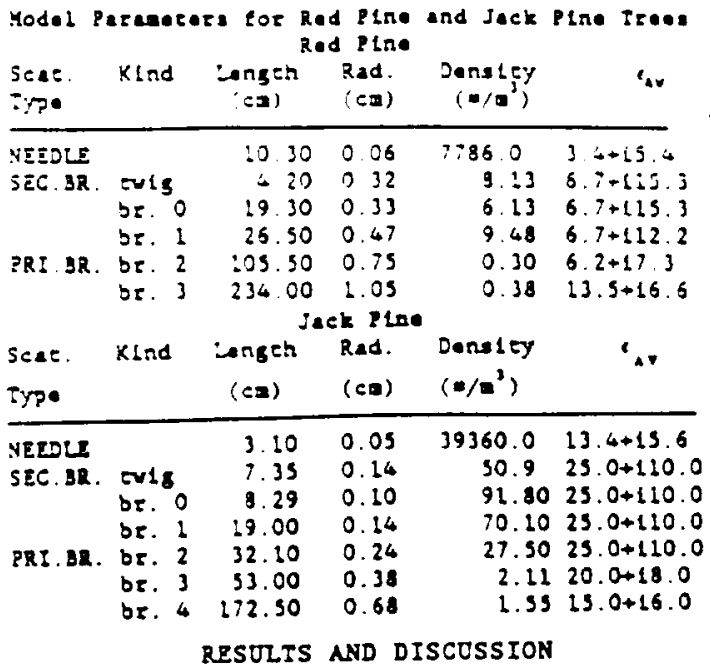

In this section the attenuation and backscatter predictions of the cWU Veretation Model for boch red pine and jack pine stands will be examined. Also, the reasons for different backscarter returns for these species and cheir sensitivity to dielectric variations will be analyzed. The discussions will involve VV polazization only.

Using the parameters given in Iable 2 , the attenuation due to each scatcerer cype in both red pine and fack pine stands have been escimated. As 1t can be seen from Table 3, the main factor causing actenuation in the red pine forest is the needles: whereas for the jack pine both needles and the primary branches play an equally lmportant role.

TABLE 3

Total Incowing Attenuetion (dB)

$$
\text { for VT Polarization }
$$

$\begin{array}{lrr} & & \\ \text { Scac. Iype } & \text { Jack P1ne } & \text { Red Ptne } \\ \text { NEEDLE } & 5.68 & 6.90 \\ \text { SEC. BR. } & 3.48 & 3.00 \\ \text { PRI. BR. } & 5.73 & 1.46 \\ \text { Tatal } & 14.89 & 11.36\end{array}$

The model predictions for the backscatter coefficiencs for each of chese specles is given in Table 4 . If the individual recurns for each of the scatcerer components are compared, one can observe that the major concribution in the red pine stand is obtained frow the needles; whereas for the fack pine forest it is the secondary branches that give the highest recurns. The fact that the needles have the highest return in the red plne stand can be explatned by the low density of the secondary branches, and also by long needles. On the other hand; the density of the secondary branches in jack pine is much higher compared to the red pine and thus theit contribution to backscatering coefficlent can surpass that of needles which are very small in size.

The sensielviey of the backscatter returns to the dlelectric constant of needles is exantined in Fig. 3. One can observe the varlations in the total backscactering coeffleient as the dielectric cotal backscaccer both red pine and jack pine scands is varled from 50 to 1300 of theis pominal values, given in Table 2 . It Is seen that che red pine returns increase by as much as $5 \mathrm{~dB}$, while the response from the fack pine stays almost constant.
TABLE 4

Backscatter Coefflelent ( $A B$ ) for VV Polarization Kind

Red Pire jack Rine

\begin{tabular}{|c|c|c|c|}
\hline NEEDLE & & -17.99 & -22.58 \\
\hline sES. $\mathrm{QP}$. & $\begin{array}{l}=\because: \sigma \\
\text { hr. } 0 \\
\text { br. } 1\end{array}$ & $\begin{array}{l}-32.93 \\
-25.98 \\
-26.68\end{array}$ & $\begin{array}{l}-23.7 \\
-22.86 \\
-15.32\end{array}$ \\
\hline PRI. BR. & $\begin{array}{ll}b r . & 2 \\
b r . & 3 \\
\text { br. } & 4\end{array}$ & $\begin{array}{r}-36.76 \\
-20.95 \\
\star \star \star \star \star\end{array}$ & $\begin{array}{l}-18.77 \\
-38.54 \\
-20.04\end{array}$ \\
\hline Total & & -15.33 & -11.68 \\
\hline Measured & & -13.55 & -12.07 \\
\hline
\end{tabular}

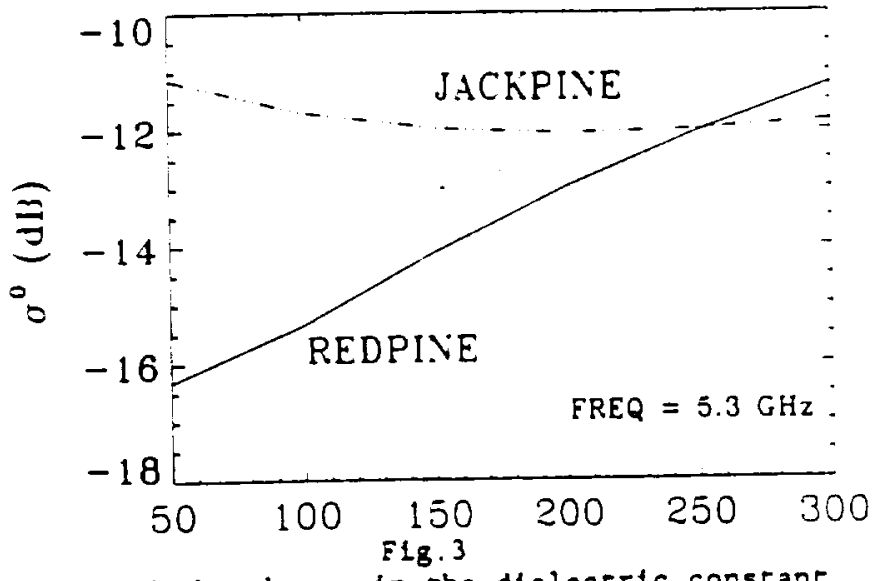

Ratlo of the change in the dielectrle constant fron the nominal value (s)

\section{REFEREXCES}

(1) Leckle. D.G., "Synerg1sm of Synthetic Aperture Radar and Vistble/Infrared. Data for Forest Type Discrimination", Phocogrametric Engineering and Remote Sensing. Vol. 56. No. 9 , 1990, pp. 1237-1246.

(2) Dobson, M.C., Plerce, L., McDonald, K. and Sharik. I. "Seasonal Change in Radar Backscatee from Mixed Conifer and Hardwood Forests in Northern Michlgan", Proc. IGARSS, 1991. Helsiniki. Finland, PP. 1121-1124.

[3] Lang, R.H., KIlic, O., Chawhan, N.S. and Ranson, J., "Modeling of SAR Recurns from a Red Pine Stand", Proc. IGARSS, 1992, Houston, Texas. pp. 1138-1140. (Accepeed for publication in the Remote Sensing of the Environment)

(4) Salas, W.A., Ranson, K.J.. Rock, B.N. and Moss D.M. "Diumal Changes in the Dlelectric Propeztles and Water Status of Eastern Hemlock and Red Spruce from Howland, ME", Proc. IGARSS. 1991. Helsink1, Finland, pp. 1111-i114.

(5) McDonald, K.C.. Zlmermann, R., Way J. and Oren, R. "An Investigation of the Relationship Between. Tree Hater Potentlal and Dielectrie Constane", Proc. IGARSS, 1992, Houston. Texas, PP. 523-525.

[6] Landry, R., Fourier, R. and Ahern, F.J.. iree Vectorization: A Hethod co Describe the Tree Archltecture", to be subaliced to ine Canadian Journal of Remoce Sensing. 1993. 